
Cooke, A. C., Preshaw, R. M., and Grossman, M. I. (1966). Gastroenterology,

Davenport, H. W. (1964). Gastroenterology, 46, 245

Davenport, H. W. (1965 a). Gut, 6, 513

Davenport, H. W. (1965 b). Gastroenterology, 49, 189

Gedda, P. O., and Moritz, U. (1959). Acta Rheumatologica Scandinavica, 4, 249.

Hollander, F. (1952). Federation Proceedings, 11, 706

Ivey, K. J. (1971). Gastroenterology, 61, 247.

Ivey, K. J., and Bhanthumnavin, K. (1971). Australian and New Zealand Fournal of Medicine, 1,300 .

Ivey, K. J., and Clifton, J. A. (1971). Fournal of Laboratory and Clinical Medicine. 78, 753 .

Ivey, K. J., and Gray, C. (1972). American fournal of Digestive Diseases, 17,

Ivey, K. J., and Gray, C. (1973). Australian and New Zealand fournal of Medicine, In press.

Ivey, K. J., Den Besten, L., and Clifton, J. A. (1970 a). Gastroenterology, 59,683 .
Ivey, K. J., Clifton, J. A., and Den Besten, L. (1970 b). Gut, 59, 203.

Ivey, K. J., Morrison, S., Gray, C. (1972). Fournal of Applied Physiology, 33,81 .

Kern, F., Clark, G. M., and Lukens, J. G. (1957). Gastroenterology, 33, 25. Krammerer, W. H., Freiberger, R. H., and Rivelis, A. L. (1958). Arthritis and Rheumatism, $1,122$.

Overholt, B. F., Brodie, D. A., and Chase, B. J. (1969). Gastroenterology, 56,651 .

Rhodes, J., et al., (1969). Gastroenterology, 57, 241.

Schmid, F. R., Cooper, N. S., Ziff, M., and McEwen, C. (1961). American Fournal of Medicine, 30, 56.

Smith, B. M., Skillman, J. J., Edwards, B. G., and Silen, W. (1971). New England fournal of Medicine, 285, 716.

Taylor, R. T., Huskisson, E. I., Whitehouse, G. H., Hart, F. D., and Trapnell, D. H. (1968). British Medical Fournal, 4, 734

Teorell, T. (1939). Fournal of General Physiology, 23, 265.

\title{
Effect of Several Drugs on Gastric Potential Difference in Man
}

\author{
H. S. MURRAY， M. P. STROTTMAN， A. R. COOKE
}

British Medical fournal, 1974, 1, 19-21

\section{Summary}

Measurement of gastric mucosal potential difference was used to study the exiect on the gastric mucosal barrier in six volunteer subjects of several drugs known to provoke ulcers. Potential differences were also recorded in nine patients with rheumatoid arthritis being treated with long-term aspirin and five patients on long-term prednisone. Unbuffered aspirin and ethanol "broke" the barrier as shown by a rapid fall in potential difference. The effects of aspirin were dose related, with $600 \mathrm{mg}$ causing a greater reduction than $300 \mathrm{mg}$. The effects of aspirin and ethanol given together were additive and caused the greatest fall in potential difference. Sodium acetylsalicylate did not alter the normal potential difference. Indomethacin, phenylbutazone, and prednisone all failed to cause any change in potential difference. The patients on long-term aspirin and prednisone had readings within the normal range and responded the same as normal subjects to an acute challenge. These studies show that aspirin and ethanol will damage the gastric mucosal barrier but that indomethacin, phenylbutazone, and prednisone do not.

\section{Introduction}

One of the current theories on gastric ulcer involves the reflux of bile and duodenal contents into the stomach with the subsequent formation of gastritis and peptic ulcer due to damage of the gastric mucosal barrier by the refluxed material ( $\mathrm{Du}$ Plessis, 1965; Capper, 1967). The damage induced by bile is reflected by changes in net $\mathrm{Na}^{+}$and $\mathrm{H}^{+}$ion flux - that is, the loss of $\mathrm{H}^{+}$ion from the lumen (back diffusion) and a net gain of $\mathrm{Na}^{+}$ion into the lumen (Ivey et al., 1970). Various other agents have been found in both animals and man to cause damage to the gastric mucosal barrier (Davenport, 1970). Gastric transmucosal potential difference (P.D.) meas-

Department of Internal Medicine, Veterans and University Hospitals University of Iowa, Iowa City, Iowa 52242, U.S.A.

H. S. MURRAY, M.D., Fellow

M. P. STROTTMAN, M.D., Assistant Professor

A. R. COOKE, M.D., Associate Professor ured in $\mathrm{mV}$ falls when damage occurs, and studies performed in animals have shown a correlation between changes in $\mathrm{Na}^{+}$ and $\mathrm{H}^{+}$flux and a lowering of the gastric mucosal P.D. when the barrier is "broken" (Davenport et al., 1964; Chvasta and Cooke, 1972). When measuring electrolyte fluxes in animals, isolated gastric pouches are used which facilitates more accurate determination of electrolyte movement. In the intact stomach in man, however, measurement of electrolyte fluxes has the following problems which may give inaccurate results: loss by incomplete recovery, loss by neutralization, and addition by secretion. Measurement of gastric mucosal P.D. does not have these limitations, and, because of the correlation between P.D. and $\mathrm{Na}^{+}$and $\mathrm{H}^{+}$ion fluxes, the measurement is a simple, rapid, and reproducible one for evaluating the integrity of the gastric mucosal barrier in man.

The aetiology of drug-induced gastric erosions and ulceration may involve changes in the gastric mucosal barrier in man, and, in fact, unbuffered aspirin has been found to cause such changes (Geall et al., 1970; Ivey et al., 1972) There have not been any studies testing the barrier with regard to the other "ulcerogenic" drugs apart from one study in dogs (Chvasta and Cooke, 1972).

In the present study we have used the measurement of P.D. to assess the integrity of the gastric mucosal barrier in normal volunteers after the instillation into the stomach of several drugs thought to be ulcerogenic. We have also determined P.D. in patients ingesting high doses of aspirin or prednisone over a period of several years to determine if high doses of these types of drugs for long periods could cause changes in the mucosa reflected by a changed P.D. (A preliminary report of the study was presented at the annual meeting of the American Gastroenterological Association in New York (Murray et al., 1973).)

\section{Methods}

Studies were made in six fasted healthy volunteers, one woman and five men, aged from 21 to 26 years. Further experiments were done in nine patients with rheumatoid arthritis on long-term aspirin and in five patients on long-term prednisone.

The method used to measure P.D. was similar to that used in animals (Davenport et al., 1964; Chvasta and Cooke, 1972) and in man (Andersson and Grossman, 1965; Geall et al., 
1970), and consisted of exploring and reference electrodes filled with saturated $\mathrm{KCl}$ in $3^{\prime \prime}$, agar. The reference electrode was a sterile Abbott Butterfly-19 infusion set and was inserted into a peripheral vein. The exploring electrode was Tygon flexible plastic tubing and was attached to a radio-opaque Argyle stomach tube (16 F.G.) by tetrahydrofuran. Positioning of the exploring electrode and the nasogastric tube was done under fluoroscopic control. They were initially placed in the antrum and then withdrawn until the tips of the tubes were situated along the greater curvature of the stomach two to three inches proximal to the antrum. Both the reference and exploring electrodes led to two beakers containing saturated $\mathrm{KCl}$. Also placed in each beaker was a balanced calomel halfcell electrode (Radiometer, Copenhagen) which led to a potentiometer (Radiometer, Copenhagen) from which P.D. could be read continuously. Recordings were made at threeminute intervals during all the studies performed.

The drugs under study were delivered via the nasogastric tube in the region where P.D. was being recorded while the subjects lay on their left side. As a preliminary measure, gastric P.D. was monitored continuously until it was stable. A $100 \mathrm{ml}$ dose of $154 \mathrm{mM} \mathrm{NaCl}$ was then instilled as a control and P.D. was measured for $15 \mathrm{~min}$. This was followed by the instillation of $100 \mathrm{ml}$ of $154 \mathrm{mM} \mathrm{NaCl}$ plus the drug under study, and recordings were made for $30 \mathrm{~min}$.

The following agents were tested in the above manner. Aspirin as powdered acetylsalicylic acid suspended in $100 \mathrm{ml}$ of normal saline at dosages of 300 and $600 \mathrm{mg}$. Sodium acetylsalicylate $(728 \mathrm{mg}$, Alka-Seltzer) dissolved in $100 \mathrm{ml}$ of $\mathrm{H}: \mathrm{O}$. Ethanol $(100 \mathrm{ml})$ at a concentration of $15 \% \mathrm{w} / \mathrm{v}$ plus or minus $600 \mathrm{mg}$ of aspirin. Prednisone $30 \mathrm{mg}$, indomethacin $50 \mathrm{mg}$, and phenylbutazone $200 \mathrm{mg}$ all in the powdered form suspended in $100 \mathrm{ml}$ of normal saline.

P.D. measurements were also made in nine patients with rheumatoid arthritis on long-term aspirin $(5,400 \mathrm{mg} /$ day for an average of seven years), and five patients on long-term prednisone therapy $(20 \mathrm{mg} /$ day for periods ranging from two months to six years). Potential difference was again recorded for $15 \mathrm{~min}$ after the instillation of saline, and then their response to an acute challenge with $1,200 \mathrm{mg}$ of aspirin in the former and $20 \mathrm{mg}$ of prednisone in the latter was measured.

The differences between control and experimental P.D. was evaluated by Student's $t$ test (Snedecor and Cochran, 1967).

\section{Results}

\section{STUDIES IN NORMAL SUBJECTS}

Gastric mucosal potential difference (P.D.) in control studies was about $-40 \mathrm{mV}$, mucosa negative with respect to serosa.

Effects of Acetylsalicylic Acid, Ethanol, and Sodium Acetyl salicylate.-Aspirin caused a rapid and significant fall in P.D., which was dose related (fig. 1). The effect was maximal 12 min after instillation of $300 \mathrm{mg}(P<0.01)$ and $15 \mathrm{~min}$ after instillation for $600 \mathrm{mg}(\mathrm{P}<0.005)$. Ethanol 15".. (w/v) also caused a rapid and significant fall $(P<0.001)$ in $P . D$., and when combined with $600 \mathrm{mg}$ of aspirin the effects were additive $(P<0.001)$ (figs. 1 and 2). P.D. gradually returned to normal with time, and in three subjects followed for longer than $45 \mathrm{~min}$ their P.D. returned to normal. Sodium acetylsalicvlate was given as a single dose of $728 \mathrm{mg}$ and there was no reduction in P.D.-in fact, it increased by a small but significant amount $(\mathrm{P}<0.02$ ) (fig. 1). The $\mathrm{pH}$ of the gastric contents $30 \mathrm{~min}$ after sodium acetylsalicylate was about $\mathrm{pH} 6$.

Effects of Indomethacin, Phenylbutazone, and Prednisone.All three of these drugs failed to cause any change in P.D. during the period of study (fig. 3).

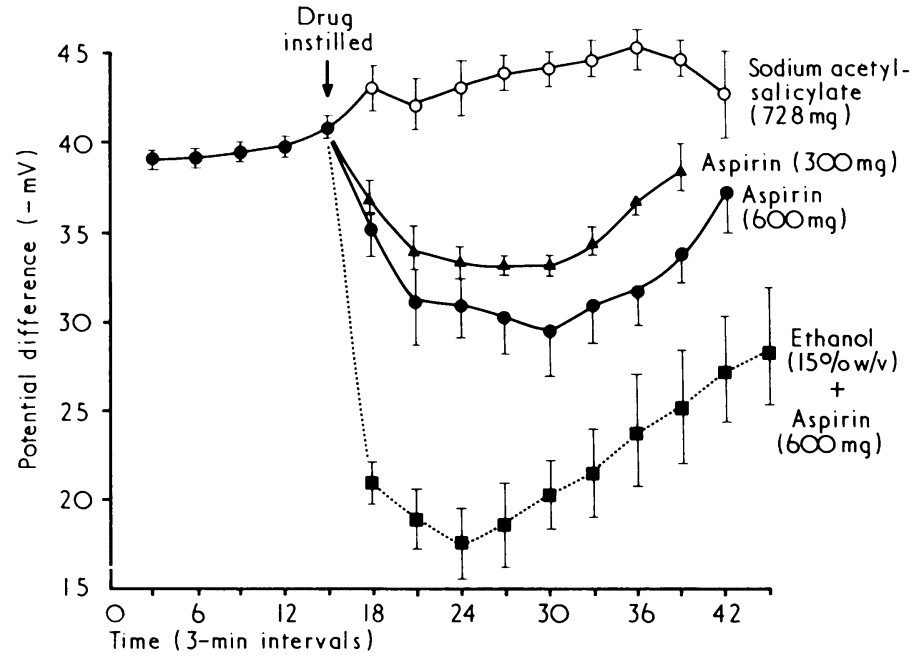

FIG. 1-Effect of sodium acetylsalicylate, acetylsalicylic acid, and ethanol plus acetylsalicylic acid on transmucosal potential difference. Each point is mean of five to seven experiments on five subjects. Vertical bars represent mean \pm S.E. of mean in this and subsequent figures.

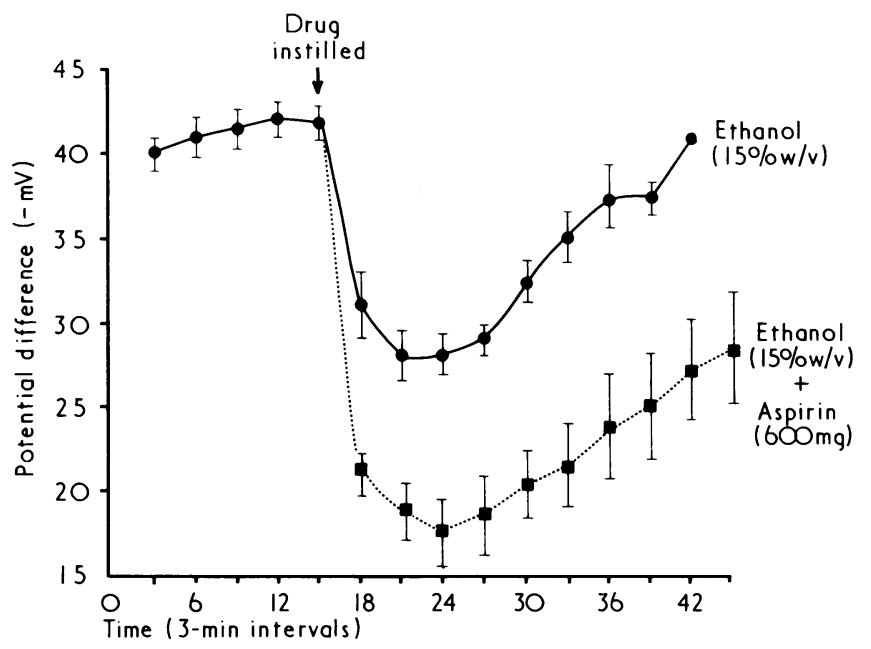

FIG. 2-Effect of ethanol and ethanol plus acetylsalicylic acid on transmucosal potential difference. Each point is mean of seven experiments in six subjects for ethanol and five experiments on five subjects for ethanol plus aspirin.

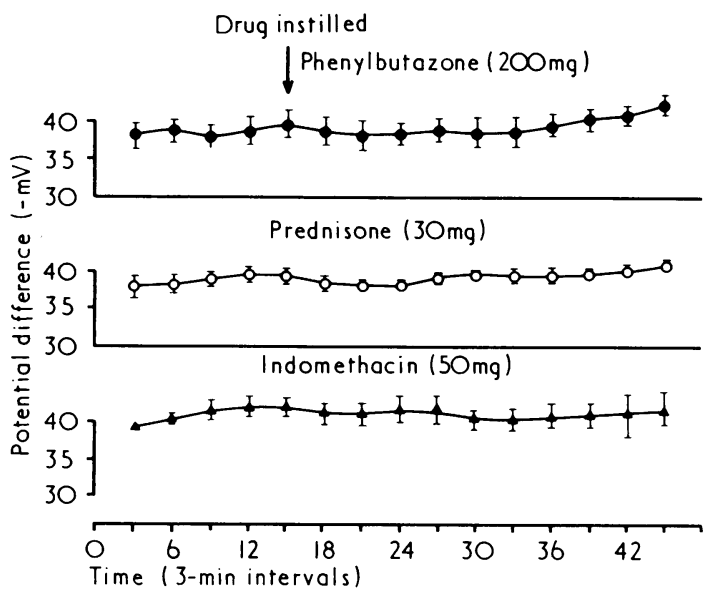
FIG. 3-Effect of indomethacin, phenylbutazone, and prednisone on trans-
mucosal potential difference. Each point is mean of five experiments on five mucosal 


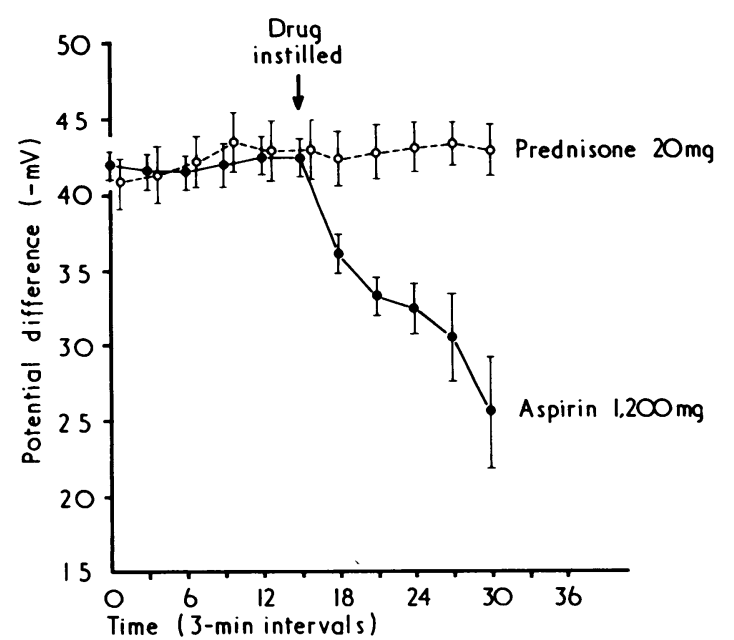

FIG. 4-Measurement of transmucosal potential difference in nine patients (nine experiments) on long-term aspirin and five patients (five experiments) on long-term prednisone. Effect of acute challenge with aspirin in former and prednisone in latter.

\section{STUDIES IN PATIENTS}

All nine patients with rheumatoid arthritis on long-term aspirin and all five on long-term steroids had P.D.s well within the normal range during control periods (fig. 4). The patients on long-term aspirin when challenged with $1,200 \mathrm{mg}$ of aspirin had a significant rapid fall in P.D. $(P<0.005)$ whereas the patients on prednisone given $20 \mathrm{mg}$ of prednisone showed no change (fig. 4). Thus, the patients reacted in the same way to a challenge with aspirin or prednisone as did the normal subjects.

\section{Discussion}

Damage to gastric mucosa in man can be assessed by an increase in occult blood loss measured by ${ }^{51} \mathrm{Cr}$-tagged red cells in the stool, by the presence of gastritis or erosions at endoscopy, by increased net $\mathrm{Na}^{+}$and $\mathrm{H}^{+}$fluxes across the stomach, and by a decrease in gastric mucosal potential difference (Cooke, 1973 a).

Measurement of P.D. is probably the most sensitive of these methods. In animals it has been found that when the gastric mucosal barrier is "broken" there is a correlation between changes in net $\mathrm{Na}^{+}-\mathrm{H}^{+}$fluxes and a decrease in P.D. (Davenport et al., 1964; Chvasta and Cooke, 1972).

Geall et al. (1970) performed the only other study in man assessing damage to the barrier by changes in P.D. They showed a fall after the instillation of aspirin, alcohol, and bile, which has been found in man and animals to be associated with changes in net $\mathrm{Na}^{+}$and $\mathrm{H}^{+}$fluxes, confirming that the gastric mucosal barrier was broken (Davenport et al., 1964; Davenport, 1967; Ivey et al. 1970; Chvasta and Cooke, 1972; Weisbrodt et al., 1973).

In the present study the gastric mucosal barrier as measured by P.D. was broken by unbuffered aspirin and ethanol, and the effect of the two together was additive. Furthermore, the effect of aspirin was dose related. In contrast, buffered sodium acetylsalicylate in a dose of $728 \mathrm{mg}$ did not cause any fall in P.D. This finding is in agreement with the results of Davenport (1969) who found that buffered sodium acetylsalicylate (pH 6-7) did not alter $\mathrm{Na}^{+}$and $\mathrm{H}^{+}$fluxes in pouched dogs. Aspirin has a pKa of $3.5-$ that is, at pH $3.550 \%$ is in the ionized form and $50 \%$ in unionized form. In order for aspirin to cause damage and bleeding to the stomach it must be in its unionized fat soluble form, and acid in sufficient concentra- tion must be present. Sodium acetylsalicylate is buffered by citrates to $\mathrm{pH}$ 6-7. Thus, the active ingredient is completely ionized and thus not absorbable and acid is neutralized. These findings of no change in P.D. are consistent with those of others, which indicate that sodium acetylsalicylate does not cause gastric erosions or occult bleeding in man (Bouchier and Williams, 1968; Leonards and Levy 1969; Cooke, 1973 b).

The other "ulcerogenic drugs" prednisone $20 \mathrm{mg}$, indomethacin $50 \mathrm{mg}$, and phenylbutazone $200 \mathrm{mg}$, were given at therapeutic dosages which are said to injure gastric mucosa. All three failed to cause any lowering of P.D., suggesting that they do not affect the barrier. In a previous study measuring oocult blood loss prednisolone $(5-20 \mathrm{mg} /$ day) and phenylbutazone (200-400 mg/day) did not increase bleeding (Scott et al., 1961). Wanka et al. (1964) found a very small increase in fecal blood loss in only five out of 13 patients given indomethacin. Chvasta and Cooke (1972) found that phenylbutazone and corticosteroids did not damage the barrier in isolated fundic pouches in dogs whereas indomethacin did. In this latter study the dose of indomethacin used would be equivalent to five times that used in the present study. Whether this drug would break the barrier at higher doses can be only speculated on.

In the study with patients long-term aspirin and prednisone appeared not to cause any damage to the stomach since both groups had P.D. readings well within normal range. Furthermore, when challenged with aspirin or prednisone they reacted in the same way as did the normal subjects. Thus, despite the fact that unbuffered aspirin is capable of causing acute falls in P.D., increased fecal blood loss, and gastric erosions, it does not appear to result in damage to the stomach as assessed by P.D. when given on a long-term basis. The question of whether aspirin or conticosteroids cause chronic peptic ulceration is a controversial one, but recent reviews of the literature suggest that corticosteroids probably do not (Cooke, 1967, 1973 a; Cushman, 1970) and that further studies are needed with respect to unbuffered aspirin (Cooke, 1970, 1973 a).

This work was supported by grants from the U.S.P.H.S. (Grant No. AM 15886) and Veterans Administration Research Funds.

\section{References}

Andersson, S., and Grossman, M. I. (1965). Gastroenterologv, 49, 364 Bouchier, I. A. D., and Williams, H. S. (1968). Lancet, 2, 603. Capper, W. M. (1967). Annals of the Royal College of Surgeons of England, 40,21 .

Chvasta, T. E., and Cooke, A. R. (1972). Fournal of Laboratory and Clinical Medicine, 79, 302

Cooke, A. R. (1967). American fournal of Digestive Diseases, 12, 323.

Cooke, A. R. (1970). Australasian Annals of Medicine, 19, 269.

Cooke, A. R. (1973 a). Gastrointestinal Discase, Saunders, Pa. ed. J. S. Fordtran and M. H. Sleisenger. p. 642.

Cooke, A. R. (1973 b). American fournal of Digestize Diseases, 18, 225.

Cushman, P. (1970). Gut, 11, 534

Cushman, P. (1970). Gut, 11, 534 . Warner, H. A., and Code, C. F. (1964). Gastrocnterology 47,142 .

Davenport, H. W. (1967). Proceedings of the Society for Experimental Biology and Medicine, 126, 657.

Davenport, H. W. (1969). Gastroenterology, 56, 439.

Davenport, H. W. (1970). Progress in Gastrocnterology, 2, 42

Du Plessis, D. J. (1965). Lancet, 1, 974.

Geall, M. G., Phillips, S. F., and Summerskill, W. H. J. (1970). Gastroenterologv, 58, 437 .

Ivey, K. J., DenBesten, L., and Clifton, J. A. (1970). Gastrocnterology, 59, 683.

Ivey, K. J., Morrison, S., and Gray, C. J. (1972). Fournal of Applicd Physiology, 33, 81 .

Leonards, J. R., and Levy, G. (1969). Clinical Pharmacology and Therapeutics, 10,571.

Murray, H. S., Strottman, M. P., and Cooke, A. R. (1973). (iastrocnterology,

64, 776. crly fournal of Medicine, 30, 167 .

Snedecor, G. W., and Cochran, W. G. (1967). Statistical Mithods, 6th edn. Ames, Iowa State University Press.

Wanka, J., Jones, L. I., Wood, P. H. N., and Dixon, A. St. J. (1964). Annals of the Rheumatic Discases, 23, 218 .

Weisbrodt, N. W., Kienzle, M., and Cooke, A. R. (1973). Procicidings of the Society for Expirimintal Biology and Midicini, 142, 450 . 